\title{
Lightweight self-compacting concrete with light expanded clay aggregate (LECA)
}

\author{
Khaled Heiza, Fatma Eid and Taha Masoud \\ Faculty of Engineering, Menoufia University, Menoufia, Egypt
}

\begin{abstract}
Lightweight concretes have been successfully applied in building constructions for many years due to their favorable material properties, particularly their low specific weight in connection with a high strength, a high capability of thermal insulation and a high durability. The development leading to lightweight self-compacting concrete (LWSCC) represents an important advanced step within the recent years. This concrete combines the favorable properties of a lightweight concrete with those of a self-compacting concrete. Research work is aimed on development of (LWSCC) with the use of light aggregates "Light expanded clay aggregate (LECA)". In this research, first by specific gravity factor method, twenty different mix designs of (LWSCC) were cast and tested to find out the values of slump flow, J-ring, V-funnel and 28 day compressive strength. Based on the results obtained, the best mix design was selected for further investigation. This paper also focuses on studying the effect of changing the reinforcement ratio on reinforced two way slabs when the dimensions were kept constant.
\end{abstract}

\section{Introduction}

Lightweight self-compacting concrete (LWSCC) is predicted to produce high workability while not segregation and high durability with reduced weight. The success to production of high quality (LWSCC) lies within the use of aggregates. Expanded clay (LECA) is a ceramic material created by expanding and vitrifying select clay in a rotary kiln. The utilization of expanded clay aggregate with other quality supplementary cementing materials (such as fly ash and silica fume) can provide highly workable and durable( LWSCCs). Expanded clay (LECA) and other light weight aggregates such as: expanded shale, pumice, slate, perlite, bottom ash etc. have been successfully used in the production of lightweight concretes (LWCs) over the decades [1,2 and $3]$. Use of those aggregates has property to the sustainable development by protective energy, increasing structural potency and increasing the service lifetime of structural lightweight concrete (LWC). These advantages add to those of (LWSCC) to additional support property development and contribute to projects obtaining Leadership in Energy and Environmental Design (LEED) certification (ESCSI 2004)[4,5]. (LWSCC) is capable of filling up the formwork and encapsulate reinforcement by its self-weight without the need for additional compaction or external vibration. It has excellent segregation resistance, high flowability and passing ability at fresh state as well as better mechanical and durability properties in the hardened state $[6,7]$.

\section{Research program}

This research was conducted in two phases: Phase (I) focused on the experimental study of the fresh and hardened properties of LWSCC mixes. Twenty concrete mixtures were designed. Three key mix design parameters namely water $(w)$ to binder (b) ratio $(w / b)(0.28-0.35)$, dosage of high range water reducing admixtures (HRWRA) (0.3-1.2\% by total content of binder) and total binder content (B) $(410-510 \mathrm{~kg} / \mathrm{m} 3)$ were selected to study the influence on the properties of ( LWSCC). The tested (LWSCC) properties were, slump flow, V-funnel flow time, J-ring flow diameter/height difference, unit weight and compressive strength. Phase( II ) based on the results obtained, the best mix which achieve the properties of light weight concrete and self-compacting concrete (so-called standard mix design) was selected for further investigation. By the standard mix the effect of changing reinforcement ratio of two way slabs reinforced by welded wire mesh with variable diameter of wire will be studied.

\section{Materials}

\subsection{Cement}

Portland cement type I (CEMI42.5N), provided by the Suez Cement Company., meeting the requirement of E.S. $7417 / 2001[12]$. 


\subsection{LECA}

The coarse lightweight aggregate used in this study was locally produced from expanded clay type (LECA) from National Cement Company. The maximum nominal size of (LECA) was $16 \mathrm{~mm}$. The sieve analysis of( LECA) is given in Table (1). In this study, the dry (LECA) was pre-soaked in water for 48 hours before mixing in concrete until steady weight of LECA was achieved, to ensure that all voids inside (LECA) particles are fully filled with water. The physical and mechanical properties of coarse aggregate are given in Table (2).

Table 1. Sieve analysis of ( LECA)

\begin{tabular}{|c|c|c|c|c|c|}
\hline $\begin{array}{c}\text { Sieve size } \\
(\mathrm{mm})\end{array}$ & 19 & 16 & 9.5 & 4.75 & 2.36 \\
\hline$\%$ & 100 & 98 & 79 & 30 & 7 \\
\hline
\end{tabular}

Table 2. Physical and mechanical properties of (LECA)

\begin{tabular}{|c|c|c|c|}
\hline Description & $\begin{array}{c}24 \text { h water } \\
\text { absorption: } \%\end{array}$ & $\begin{array}{c}\text { Specific } \\
\text { gravity }\end{array}$ & $\begin{array}{c}\text { unit } \\
\text { weight } \\
\mathrm{kg} / \mathrm{m} 3\end{array}$ \\
\hline LECA & 18.2 & 1.08 & 667 \\
\hline
\end{tabular}

\subsection{Fine aggregates}

Natural siliceous sand from El-khatatba was used as a fine aggregate.

\subsection{Fly ash}

Fly ash complying with chemical and physical requirements of American specification [ASTM C618] [13] was used.

\subsection{Silica fume}

Micro silica (silica fume) is a product of ferro silicon alloys industry. The product is a rich silicon dioxide powder where the average particles size is around 0.1 micrometers

\subsection{Viscosity agent}

Sika Viscocrete 3425 was used as viscosity enhancing agent (VEA). It contains a polycarboxylic -based copolymer-based mixture and modified cellulose product to achieve the dual action effect of high-range water reducer and viscosity-modifying admixture, respectively. It meets the requirements for super plasticizers according to Swiss specification [ SIA 162(2989)] , European specification [EN934-2], and American specification [ ASTM- C-494 type G and F). Mechanical and physical properties are given in Table (3).
Table 3. Typical Properties of Viscocrete (3425).

\begin{tabular}{|c|c|}
\hline Properties & Value \\
\hline Appearance & Clear liquid \\
\hline Density & $1.08 \mathrm{~kg} /$ Lit (ASTM C494) \\
\hline PH Value & 4.0 \\
\hline Solid content & $40 \%$ by weight \\
\hline Chloride content & Zero \\
\hline
\end{tabular}

\subsection{Reinforcing steel}

Welded wire mesh is arranged in one layer with different diameters of wire in the slab. This type of mesh is made of steel wires with diameter and size of mesh as shown in Table (4) The proof stress is equal to 400 $\mathrm{N} / \mathrm{mm} 2$ and its ultimate strength is $600 \mathrm{~N} / \mathrm{mm} 2$ while its modulus of elasticity equal to $170 \mathrm{kN} / \mathrm{mm} 2$.

Table 4. Properties of Wire Mesh .

\begin{tabular}{|c|c|c|c|c|}
\hline $\begin{array}{c}\text { Diameter } \\
(\mathrm{mm})\end{array}$ & $\begin{array}{c}\text { spacing } \\
(\mathrm{mm})\end{array}$ & $\begin{array}{c}\text { No. of } \\
\text { wires } \\
/ \mathrm{m} 2\end{array}$ & $\begin{array}{c}\text { wire } \\
\text { weight } \\
\mathrm{kg} / \mathrm{m}\end{array}$ & $\begin{array}{c}\text { Weight of } \\
\text { mesh } \\
\mathrm{kg} / \mathrm{m} 2\end{array}$ \\
\hline 3 & $30 \times 30$ & $34 \times 2$ & 0.0555 & 3.778 \\
\hline 4 & $40 \times 40$ & $25 \times 2$ & 0.0986 & 4.938 \\
\hline 5 & $50 \times 50$ & $20 \times 2$ & 0.1541 & 6.173 \\
\hline
\end{tabular}

\section{Concrete mix design}

Six mixes of (LWSCC) were designed using the specific gravity factor method, as described elsewhere [8, 9]. The best six mixes are shown in Table (5). The mix proportions of each mix were calculated by assuming that all its ingredients have to produce a cubic meter of concrete. Various mixes with different w/c ratio, all aggregate types used in this study were weighted on a saturated-surface-dry (SSD) basis, to achieve good moisture control in the concrete mixes. The constituent materials were mixed in a pan mixer with a capacity of $0.08 \mathrm{~m} 3$ and a mixing speed of $50 \mathrm{rev} / \mathrm{min}$ at ambient temperatures of about $25 \mathrm{C}$. The (SCA) was separately added into the concrete after about $1 \mathrm{~min}$ of mixing. Mixing was continued for another $2 \mathrm{~min}$ before the mixture was left to rest for approximately $3 \mathrm{~min}$. 
Table 5. Mixture Design.

\begin{tabular}{|c|c|c|c|c|c|c|}
\hline Mix No. & $\mathbf{C}_{\mathbf{1}}$ & $\mathbf{C}_{\mathbf{2}}$ & $\mathbf{C}_{\mathbf{3}}$ & $\mathbf{C}_{\mathbf{4}}$ & $\mathbf{C}_{\mathbf{5}}$ & $\mathbf{C}_{\mathbf{6}}$ \\
\hline $\mathrm{W} / \mathrm{c}$ & 0.35 & 0.32 & 0.32 & 0.3 & 0.3 & 0.28 \\
\hline \begin{tabular}{c} 
Binder(kg) \\
\hline $\begin{array}{c}\text { Cement } \\
(\mathrm{kg})\end{array}$
\end{tabular} & 510 & 410 & 500 & 510 & 500 & 510 \\
\hline FA (kg) & 76 & 62 & 72 & 76 & 72 & 76 \\
\hline $\begin{array}{c}\text { S F ( Kg) } \\
\text { Water (Lit) }\end{array}$ & 51 & 23 & 27 & 51 & 27 & 51 \\
\hline SP (Lit) & 3.8 & 1.2 & 6 & 5.1 & 1.5 & 3.8 \\
\hline Sand (kg) & 790 & 840 & 825 & 900 & 830 & 870 \\
\hline LECA (kg) & 390 & 474 & 412 & 450 & 415 & 410 \\
\hline
\end{tabular}

\subsection{Casting of test specimens}

a- Cubes with $10 \mathrm{~cm}$ side length were used for determination of the compressive strength of light weight self-compacting concrete.

b-By using the best mix which achieve the properties of self-compacting and light weight concrete, three slabs were cast using wooden mould with dimension (1000 $\mathrm{mm} * 1000 \mathrm{~mm} * 60 \mathrm{~mm}$ ) as shown in figure(1).The thickness of the slabs were kept constant, the thickness of mesh layers and their combinations were varied in order to get higher strength. To prepare the mould for casting, it was first oiled which makes it easy for demoulding process. Initially, the first portion of mortar was evenly placed and the layer of mesh was then placed in position and mortar spacers were used in the areas between these meshes. Table (6) shows the properties of reinforced slabs.

Table 6. Properties of reinforced Slabs.

\begin{tabular}{|c|c|c|c|}
\hline Slab No. & $\begin{array}{c}\text { Dimension } \\
(\mathbf{c m})\end{array}$ & $\begin{array}{c}\text { Spacing } \\
\text { of mesh } \\
\text { (cm) }\end{array}$ \\
\hline $\mathbf{A}_{\mathbf{1}}$ & $100 * 100 * 6$ & $\begin{array}{c}\text { Welded mesh } \\
\text { thick } 3 \mathrm{~mm}\end{array}$ & $3 * 3$ \\
\hline $\mathbf{A}_{\mathbf{2}}$ & $100 * 100 * 6$ & $\begin{array}{c}\text { Welded mesh } \\
\text { thick } 4 \mathrm{~mm}\end{array}$ & $4 * 4$ \\
\hline $\mathbf{A}_{\mathbf{3}}$ & $100 * 100 * 6$ & $\begin{array}{c}\text { Welded mesh } \\
\text { thick } 5 \mathrm{~mm}\end{array}$ & $5 * 5$ \\
\hline
\end{tabular}

(A)

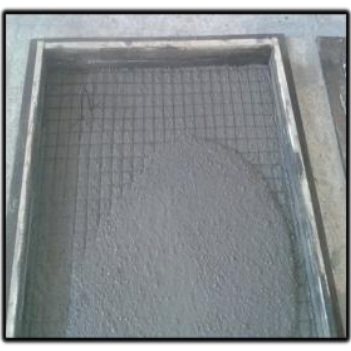

(C)

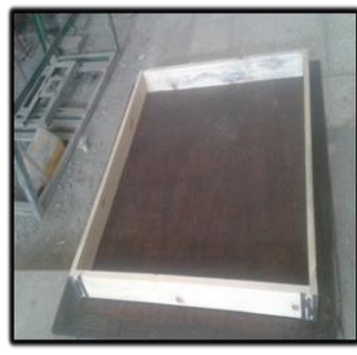

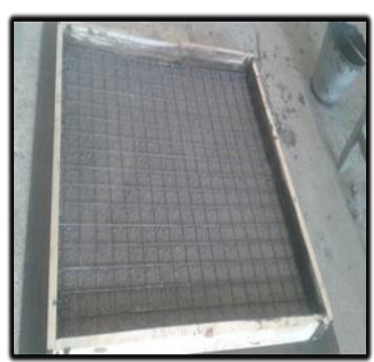

(B)

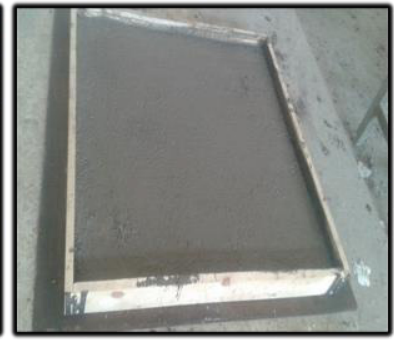

(D)
Fig.1. Casting of Specimens

\section{Results and discussion}

\subsection{Fresh characteristics of ( LWSCC)}

Immediately after the mixing, the value of slump flow, Jring and $\mathrm{V}$-funnel test were determined by the following methods Table (7).

\subsubsection{Slump flow test}

The slump flow test was used to evaluate the free deformability and flowability of (LWSCC) in the absence of obstruction.

The result of slump flow for mixtures showed that an increase in the $\mathrm{w} / \mathrm{b}$ from $(0.28$ to 0.35$)$ significantly increased the slump flow However, at fixed( HRWRA\% )the slump flow range got limited with the increase of binder content.

Great positive effect of the coupled parameters (w/b and HRWRA) in increasing the slump flow .The slump flow test for (LWSCC) is shown in Fig. 2.

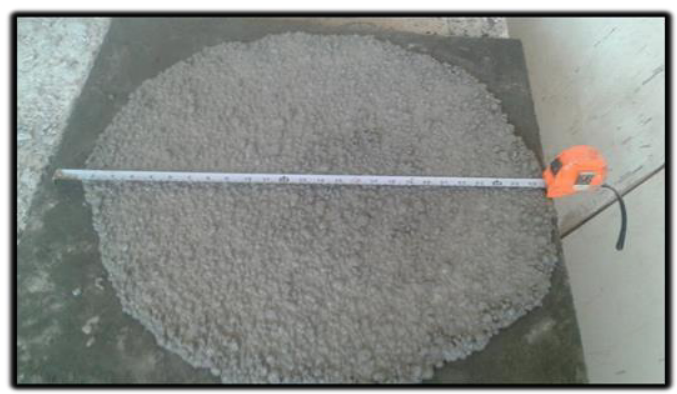

Fig. 2. Slump Flow Test. 


\subsubsection{J-ring test}

The J-ring test is used to determine the passing ability of the (LWSCC) (Fig. 3).

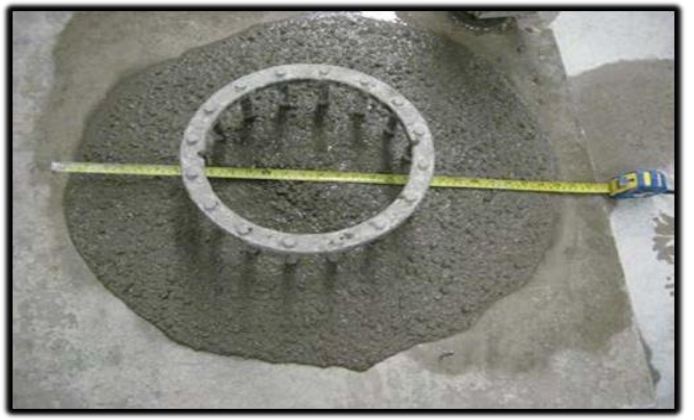

Fig. 3. J-ring test

\subsection{3 $V$-funnel flow test}

The V-funnel test is used to determine the deformability through restricted area.

An increase of the w/b from (0.28 top 0.35 ) significantly reduced the V-funnel flow time whereas an increase of (HRWRA) from 0.3 to $1.2 \%$ only slightly reduced the Vfunnel flow time. However, combined maximum increase of both (w/b and HRWRA) parameters resulted in a substantial reduction of the V-funnel flow time the test was carried out for (LWSCC) as shown in Fig. 4.

For all mixes, the slump flow and J-ring flow/J-ring height difference were positively influenced by (w/b and HRWRA). An increase of either or both parameters led to an increase in the measured responses/properties. However, an increase in the binder content alone affects the results negatively-showing a decrease in the measured responses. So that mix No C5 and C6 don't achieve values of acceptance of self-compacting concrete [10].

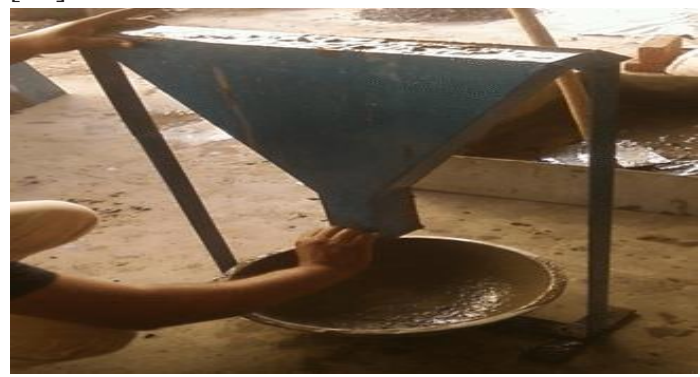

Fig. 4 . V-funnel Flow Test.
Table 7. Fresh properties of mixtures

\begin{tabular}{|c|c|c|c|c|c|}
\hline $\begin{array}{c}\text { Mix } \\
\text { No }\end{array}$ & $\begin{array}{c}\text { Slump } \\
\text { flow } \\
(\mathbf{m m})\end{array}$ & $\begin{array}{c}\text { T at } \\
\mathbf{5 0} \mathbf{~ c m} \\
\text { (sec) }\end{array}$ & $\begin{array}{c}\text { V- } \\
\text { funnel } \\
\text { (sec) }\end{array}$ & $\begin{array}{c}\text { J- } \\
\text { Ring } \\
\text { flow } \\
(\mathbf{m m})\end{array}$ & $\begin{array}{c}\mathbf{J}- \\
\text { Ring } \\
\text { height } \\
\mathbf{d i f f} \\
(\mathbf{m m})\end{array}$ \\
\hline $\mathbf{C}_{\mathbf{1}}$ & 750 & 1 & 7 & 700 & 5 \\
\hline $\mathbf{C}_{\mathbf{2}}$ & 650 & 1.5 & 8 & 630 & 8 \\
\hline $\mathbf{C}_{\mathbf{3}}$ & 700 & 1 & 7 & 650 & 6 \\
\hline $\mathbf{C}_{\mathbf{4}}$ & 690 & 1.2 & 7 & 640 & 6 \\
\hline $\mathbf{C}_{\mathbf{5}}$ & 550 & 4 & 13 & 500 & 10 \\
\hline $\mathbf{C}_{\mathbf{6}}$ & 450 & - & 15 & 430 & 12 \\
\hline
\end{tabular}

\subsection{Hardened characteristics of (LWSCC)}

As noted from the results showed in Table (8) compressive strength increases with decrease of w/c with saturated expanded clay and increases with increase of binder. The best compressive strength mix is $\mathrm{C} 6$ but it doesn't meet the requirements of self-compacting concrete .All mixtures unit weight less than $2000 \mathrm{~kg} / \mathrm{m} 3$ so that it can be light weight concrete.

The best mixture which achieves the requirements of light weight self-compacting concrete (LWSCC) with best strength is mixture no $\mathrm{C} 4$.

Table 8. Compressive strength and unit weight of different mixes.

\begin{tabular}{|c|c|c|c|c|}
\hline \multirow{2}{*}{$\begin{array}{c}\text { Mix } \\
\text { No }\end{array}$} & \multicolumn{2}{|c|}{$\begin{array}{c}\text { Compressive } \\
\text { strength } \\
\left(\mathbf{k g} / \mathbf{c m}^{\mathbf{2}}\right)\end{array}$} & \multicolumn{2}{c|}{$\begin{array}{c}\text { Unit weight } \\
\left(\mathbf{k g} / \mathbf{m}^{\mathbf{3}}\right)\end{array}$} \\
\cline { 2 - 5 } & 7- day & 28-day & fresh & air dry \\
\hline $\mathbf{C}_{\mathbf{1}}$ & 162 & 190 & 1820 & 1790 \\
\hline $\mathbf{C}_{\mathbf{2}}$ & 130 & 153 & 1850 & 1810 \\
\hline $\mathbf{C}_{\mathbf{3}}$ & 155 & 186 & 1880 & 1830 \\
\hline $\mathbf{C}_{\mathbf{4}}$ & 167 & 227 & 1910 & 1865 \\
\hline $\mathbf{C}_{\mathbf{5}}$ & 152 & 184 & 1860 & 1800 \\
\hline $\mathbf{C}_{\mathbf{6}}$ & 172 & 235 & 1900 & 1850 \\
\hline
\end{tabular}

\subsection{Behavior of reinforced light weight self- compacting concrete slabs.}

\subsubsection{Test Setup of Slabs}

A special flexure loading frame was fabricated for making the test of the slabs and the details of the test setup is shown Fig. 5. In order to test the slabs on a four point loading (at 1/3rd span), over an effective span of $850 \mathrm{~mm}$, the middle line of the slab, and also the roller supports were marked and slab was seated on the bottom rollers . Loading was applied manually through a hydraulic 
jacking arrangement to cause downward deflection (see Fig.5). The load was given through the jack in tiny increments and also the deflection of the slab was recorded up to failure using dial gauges. The proving ring readings and displacement values were observed instantaneously. The proving ring readings are taken at every five division interval and also the corresponding deformation values were determined in the displacement indicator. The loading was continued till the ultimate failure of the slab is reached, and the above measurements were taken at different load levels till final failure. The ductility (deflection) of slabs using different reinforcing mesh thickness ( $3 \mathrm{~mm}, 4 \mathrm{~mm}$ and $5 \mathrm{~mm}$ ) has been studied initially crack and ultimate failure loads.

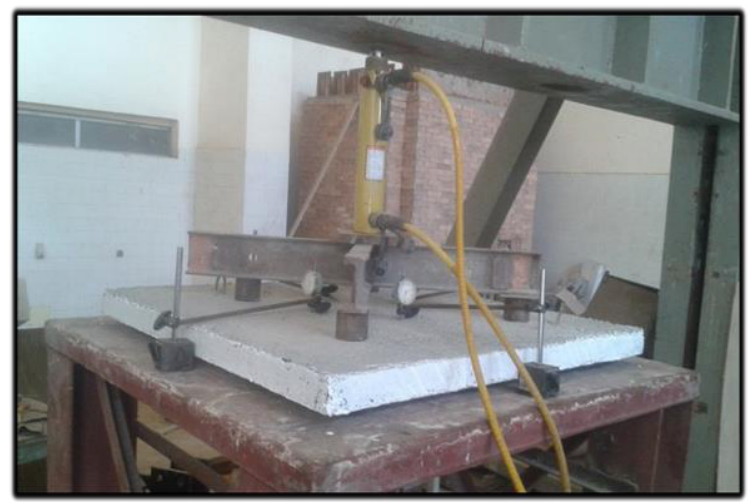

Fig. 5. Flexure test set-up of slabs.

\subsubsection{Results}

A total of three specimens were tested in this investigation on four point loading tests and the results of the experimental tests carried out are analyzed including the flexural loads and deflection (Fig.6, 8, 9 and 10). The failure of the slab specimen's results from the yielding of wire mesh reinforcement is followed by the crushing of mortar. Initially fine flexural cracks appeared at the bottom of the specimen. With further increase in the load, regularly spaced vertical cracks were observed and they extended from the bottom of the specimen towards top Fig.(7).The load was increased up to ultimate stage.

Slab No. (A3) reinforced with wire mesh $5 \mathrm{~mm}$ diameter recorded the highest value of ultimate load due to bigger diameter and pitch spacing $(50 \mathrm{mmx} 50 \mathrm{~mm})$ while slab No (A1) reinforced with wire mesh $3 \mathrm{~mm}$ diameter obtained the lowest value of ultimate load due to their smaller diameter and pitch spacing $(30 \mathrm{~mm} \times 30 \mathrm{~mm})$

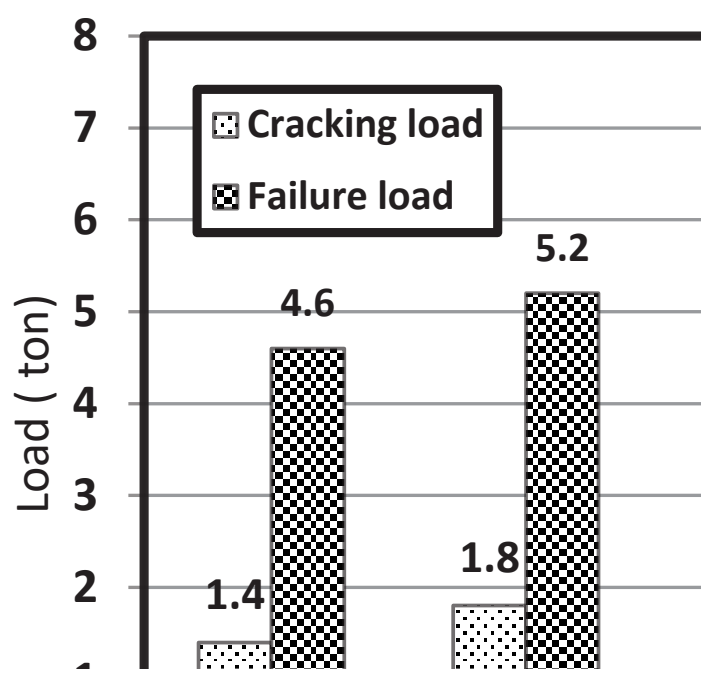

Fig. 6. Cracking and failure load for testing slabs

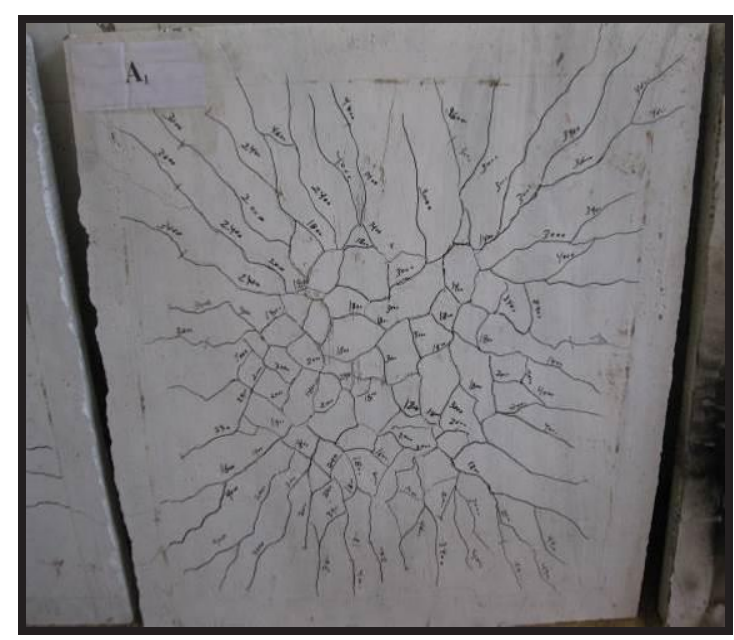

( A1 )

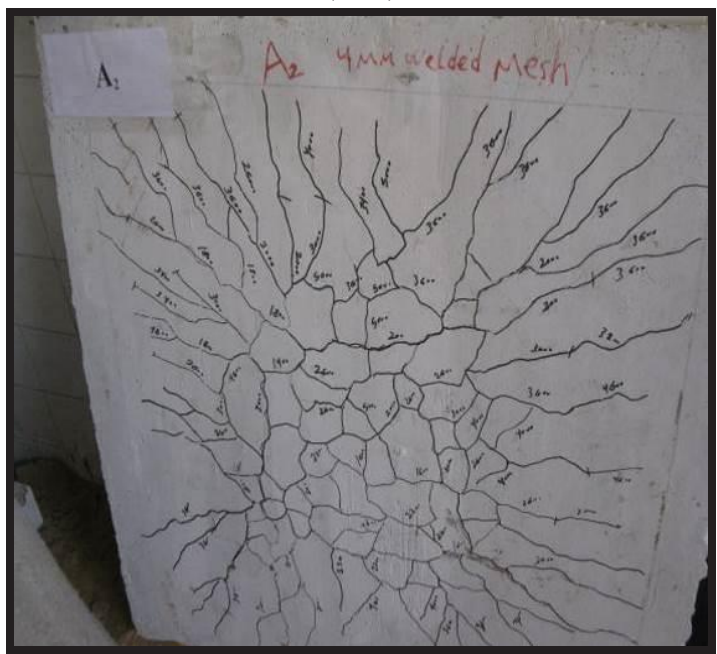

$\left(\mathrm{A}_{2}\right)$ 


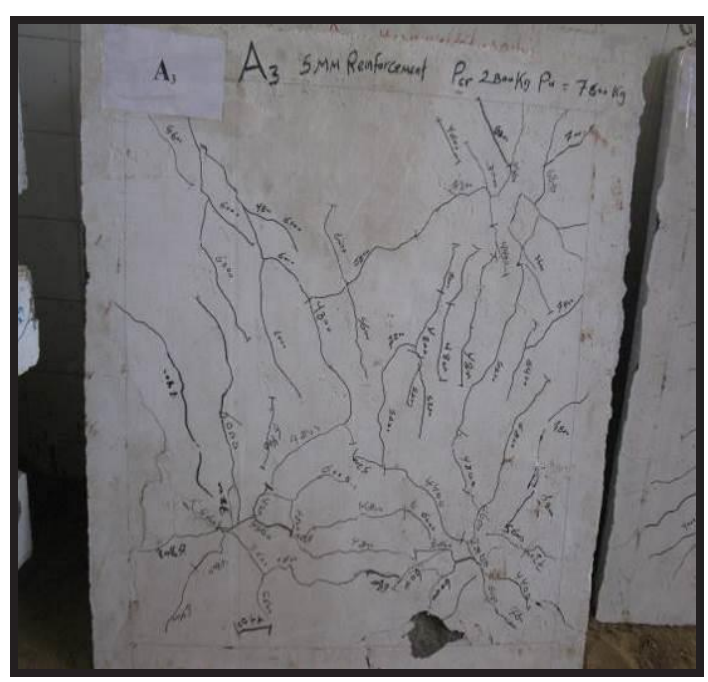

(A3)

Fig. 7. Crack pattern for slabs (A1, A2 and A3)

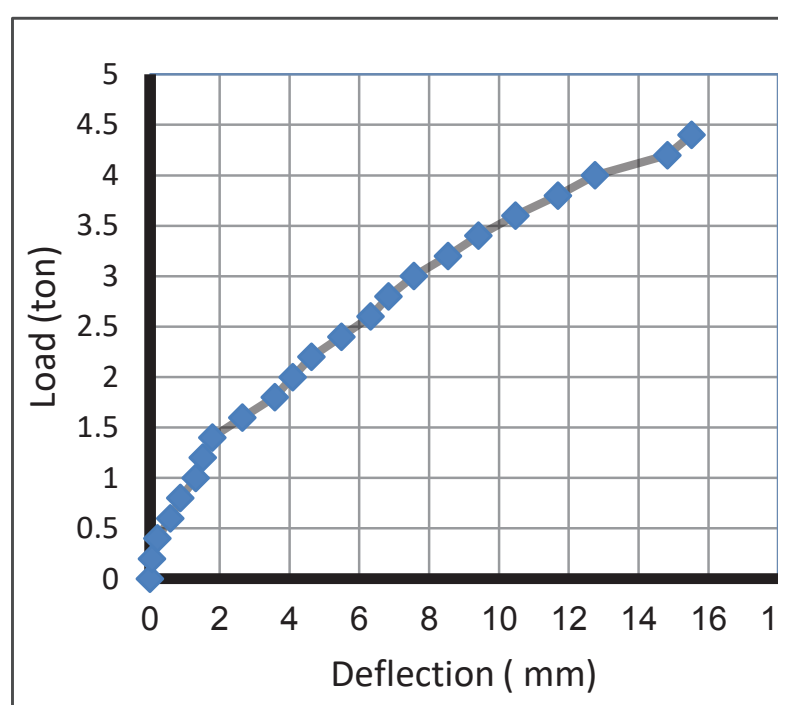

Fig. 8. Load - deflection curve of slab (A1)

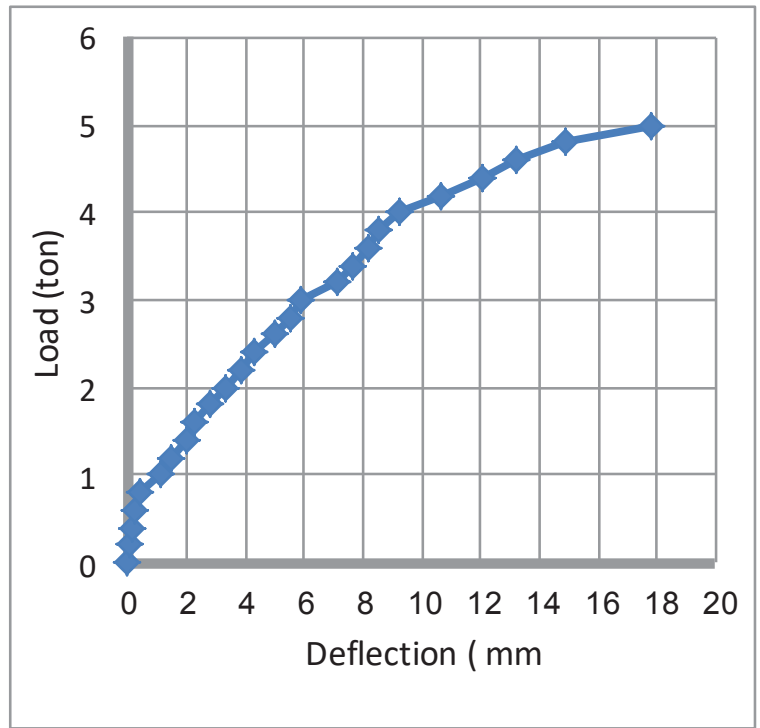

Fig. 9. Load - deflection curve of slab (A2)

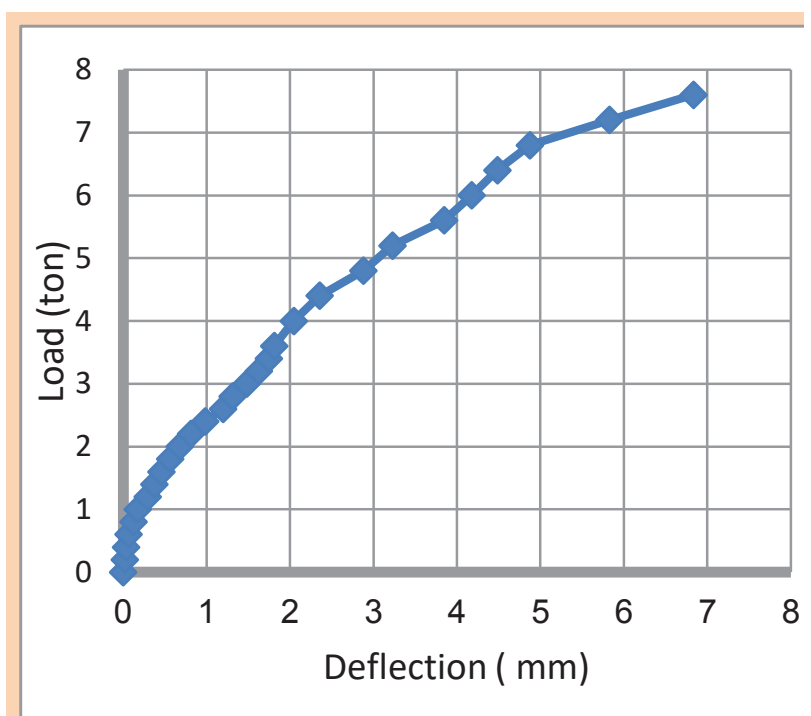

Fig. 10. Load - deflection curve of slab (A3)

\section{Conclusions}

Based on the results and observations of the experimental study presented, the following conclusions could be drawn as follows:

1 - It is possible to manufacture a structural light weight concrete with low density and high self-compacting characteristics using expanded clay aggregate ( LECA).

2 - The way of mixing of this concrete is different: lightweight aggregate (LECA) is recommended to be prewetted either in the mixing device by batching light weight aggregate (LECA) and water (and adding the rest of materials after a while) or before the process of mixing (in the store or similar). Pre-wetted light weight aggregate (LECA) gives higher stability of rheological behavior of fresh concrete and foaming of cement matrix is better to control.

3- In condition of fresh properties, the passing ability and filling capacity increase with the increases of $w / b$ and there is a great effect when (HRWRA) increased.

4-In condition of fresh properties, the total binder content had influence on workability and static stability (segregation resistance) of (LWSCCs). For a given w/b, the (HRWRA) demand decreased with the increase of total binder content. On the other hand, segregation resistance increased with the increase in total binder content.

5- In condition of hard properties the compressive strength increased with decrease in w/c, and increased with increase in binder amount.

6 - The flexural loads at first crack and ultimate loads depend on thickness of reinforcing mesh layers used in the slab.

7- By increasing the reinforcement ratio from $0.6 \%$ for slab No (A1) to $0.81 \%$ for slab No (A2), the flexural loads increased by $13 \%$.

8- By increasing the reinforcement ratio from $0.81 \%$ for slab No (A2) to $1 \%$ for slab No (A3), the flexural loads increased by $46.15 \%$. 
8 - During exposing slabs to ultimate load, it was observed that the slab did not break into pieces after failing, instead the cracks were found to widen. This is because the welded wire mesh prevents the cement mortar from breaking and falling off. By simply observing the cracks it was inferred that the slab with layer of wire mesh with $4 \mathrm{~mm}$ thickness has more crack patterns compared to slab with layer of wire mesh $5 \mathrm{~mm}$ thickness. Hence with an increase in thickness of layers of wire mesh we can improve the capacities of slabs.

\section{References}

1. M. G. Stamatakis, M. Bedelean, H., Gorea, D., Alfieris, E., Tziritis, and S., Kavouri, Refractories World forum, 3, 1, (2011).

2. Z. Wu, Y., Zhang, J., Zheng, and Y., Ding, Construction and Building Materials, 23, 5, (2009).

3. C. L., Hwang, and M. F., Hung, Construction and Building Materials, 19, 8, (2005).

4. K. M., Hossain, Cement and Concrete Research, 34, 2, (2004).

5. D. Fragoulis, M. G., Stamatakis, E., Chaniotakis and G. Columbus, Materials Characterization, 53, 2, (2004).

6. U. I. B., Topc , and L. T., Uygunog, Construction and Building Materials, 24, 7, (2010).

7. ESCSI, Worldwide, Salt Lake City, UT, Publication No. 9349, (2004).

8. Y., Bai, R., Ibrahim, and P. A., Muhammed Basheer, Proceedings of an International Workshop on Sustainable Development and Concrete Technology, Beijing, (2004).

9. K. S., Chia, and M. H. Zhang, Magazine of Concrete Research, 56, 8, (2004).

10. ACI 211.2, ACI Man. of Conc. Prac., (2013).

11. EFNARC, (2005).

12. E.S.7417/2001, Egyptian Standards, (2001).

13. ASTM C618, American society for testing and materials, ASTM International, (2003). 